\title{
IMPACT OF PODCASTING ON PRONUNCIATION SKILLS OF PRE-SERVICE EFL TEACHERS
}

\author{
Dr. Huseyin KAFES \\ ORCID: 0000-0002-0697-8312 \\ Faculty of Education \\ Akdeniz University \\ Antalya, TURKEY \\ Dr. Mustafa CANER \\ ORCID: 0000-0001-5741-5037 \\ Faculty of Education \\ Akdeniz University \\ Antalya, TURKEY
}

Received: 27/06/2019 Accepted: 06/12/2019

\section{FRESHMEN'S ABSTRACT}

This explorative qualitative study investigates EFL freshmen's perception of the impact of creating pronunciation podcasts on their pronunciation skills. The study was conducted with the participation of 80 freshmen, enrolled in a Teaching English as a Foreign Language teacher education program at a Turkish state university. Data were collected through semi-structured interviews, investigator notes, records of dashboard activities, analytics and performance tracking records of the LMS, and podcasts created by the participants as well as the recordings of the peer feedbacks on the discussion board. Analysis of the data was done through content analysis technique, presenting the thematized findings through analytical generalizations. Results have shown that the participants have positive views of creating pronunciation podcasts and that podcasting freed them to a great extent from the spatio-temporal limitations of the classroom, allowing them to study and practice pronunciation at their own convenience. The findings are discussed with reference to pronunciation, recommendations for EFL freshmen are made, and implications are offered.

Keywords: Pronunciation, podcasting, EFL freshmen

\section{INTRODUCTION}

Pronunciation which was one of the most commonly neglected aspects of language pedagogy newly gained a revival of interest because of its reprioritized role in speech perception and recognition. In parallel with this revitalization, pronunciation teaching approaches in English as a foreign language (EFL) and/or English as a second language (ESL) have modified their stance by encouraging language learners to study and practice pronunciation outside the classroom walls. Fortunately, language learners now have ample resources to practice pronunciation thanks to the rapid growth of internet-based technologies. Podcasting, one of the promising tools, enables learners to express themselves by addressing an authentic audience purposefully in a real-life environment. Numerous studies demonstrate that listening to podcasts enriches language skills, particularly pronunciation and listening skills. However, a review of the available literature shows that the impact of podcasts and podcasting on pronunciation teaching in teacher education has not been sufficiently examined. Hence, in this paper, we investigated the influence of podcasting on learners' perceptions in a web-enhanced pronunciation classroom.

In the history of English language teaching, it has been well-documented that pronunciation instruction has faced extreme fluctuations in interest. Depending on the trends, pronunciation teaching has drifted from one theoretical extreme to another. In the heydays of the Audiolingualism, pronunciation was considered paramount (Celce-Murcia, Brinton, Goodwin \& Griner, 2010; Jones, 1997). Shortly afterwards, its importance was greatly reduced (Kelly, 1969 cited in Celce-Murcia et al., 2010), and it became the orphan 
of second or foreign language teaching (Derwing \& Munro, 2005). These extreme swings led pronunciation teaching to be either overly emphasized or utterly ignored, depending on the way the pendulum swung.

As a result of this stance towards pronunciation teaching, there came a period when language teachers opted to see pronunciation as the least useful of the language skills, sacrificing pronunciation teaching, and therefore spending class time on other areas of the language (Elliott, 1995). This tendency to neglect pronunciation in the classroom spread rapidly among language policy makers and learners all around the world, adding weight to the already widely-held conception that pronunciation was the least important aspect of language learning and teaching.

This disregard started to change with pronunciation instruction research which began to appear in the early 2000's (Derwing, 2018). Though training in pronunciation teaching in ESL/EFL certificate programs manifested, studies (Breitkreutz, Derwing \& Rossiter, 2001; Buss, 2016; Foote, Holtby \& Derwing, 2011) revealed that pronunciation instruction was not given enough importance in such certificate programs. Moreover, the classroom applications fell short of closely following and realizing the practices suggested in the literature. This gross negligence also caused pronunciation teaching to become, for many teachers, an anxiety-ridden experience because they struggled with feelings of inefficacy in teaching pronunciation (see Foote et al., 2011; Huensch, 2018). Numerous studies have drawn attention to the inadequate pronunciation instruction teachers had received and the concerns teachers had because they did not know how to meet their students' pronunciation needs (see Breitkreutz et al., 2001; Burgess \& Spencer, 2000; Burns, 2006; Foote et al., 2011; Henderson et al., 2012; Huensch, 2018; MacDonald, 2002). The findings of these studies have contributed to the increase in interest pronunciation teaching has gained over the years, helping pronunciation teaching reclaiming popularity in second or foreign language instruction circles (Derwing, 2018).

Despite these contradictory propositions on pronunciation and its instruction, the perceived confusion with regard to the role and place of pronunciation in language teaching, and the spatio-temporal constraints, some scholars and language teachers have sought ways to provide learners with efficient means to practice pronunciation inside and outside the classroom (Lord, 2008). With the advent of technology, learners are now able to hear their pronunciation mistakes, assess their intelligibility and recognize their production of specific sounds and patterns of prosody (Hardison, 2004; Hismanoglu, 2010; Martin, 2004; Pennington, 1989; Ramirez-Verdugo, 2006, Seferoglu, 2005). Though the novelty of using audio materials in education seems to have been wearing off, recently "podcasting... has brought a newfound excitement to the classroom" (Ducate \& Lomicka, 2009, p. 68).

A podcast is an audio file that anyone can create ubiquitously using mobile devices, a computer, a microphone, and a software program (Ducate \& Lomicka, 2009; Faramarzi \& Bagheri, 2015). The simplicity of creating, editing, and publishing, as well as the portability, ease of access, flexibility and ease of use (pausing, rewinding, repeating), dynamism, and interactivity are some of the features that make podcasts desirable personalized learning tools in teaching pronunciation (Abbdedaim, 2013; Facer \& Abdous, 2010; Gromik, 2008; McGarr, 2009; Meng, 2005; Rosell-Aguilar, 2007, 2013; Stanley, 2006). Besides offering self-regulated learning, podcasts let students feel a sense of self-worth by enabling them to create and publish something for an authentic audience (Stanley, 2006). It is this creative dimension of podcasting that is interrelated with constructivism, which is based on the premise that learners should construct knowledge through active observation, exploration, processing and interpretation (Rosell-Aguilar, 2007). From a pedagogical perspective, podcasting enables students to produce "comprehensible output" (Swain, 1985), an essential feature for language learning (Swain \& Lapkin, 1995). As students create a podcast, they listen to themselves and edit their output, and often repeat these two steps until they figure out the desired form of their utterance, which forms the basis of Swain's (1985) comprehensible output hypothesis.

Despite ample use of podcasts in education, podcasting has yet to develop in foreign language learning and teaching. Some studies in the literature demonstrated that listening to podcasts enriches speaking and listening skills. Among the available studies on the use of podcasts in education, studies by Alm (2013), Carvalho and Aguiar (2009), Diem (2005), Faramarzi and Bagheri (2015) Godwin-Jones (2005), Gorjian, Hayati and Pourkhonic (2013), Gromik (2008), Hegelheimer (2006), Lord (2008), O'Bryan and Hegelheimer (2007), Robin (2007), Rosell-Aguilar (2013), Tanner \& Landon (2009), Young (2007) come to the fore. 
Though scarce, there is some research in Turkey that falls within the scope of podcasting in learning English as a foreign language. Bakla (2018) looked into listening to podcasts and students' perceptions and found that podcasts provided his participants with meaningful input and his participants enjoyed listening to podcasts. Similarly, Basaran and Cabaroglu (2014) investigated the influence of listening to language learning podcasts on freshmen's English self-efficacy beliefs in listening, speaking, reading, and writing. The results of their quasi experimental study showed that listening to podcasts significantly influenced the participants' perception of their listening comprehension speaking and reading skills. However, it did not have a positive impact on their perceptions of reading and understanding advanced level stories. Similarly, in a study on the impact of podcasts on Turkish EFL learners' oral performance, anxiety in speaking, perceptions of podcast usage, and the relationship between speaking anxiety and oral performance, Harika and Kocoglu (2016) revealed a meaningful relationship between podcasts and oral performance, and podcasts and anxiety levels in students. They have also shown that the students who used podcasts had positive views of podcasts: students believed that podcasts helped them lower their anxiety, increase their confidence, improve their oral performance and pronunciation, and expand their vocabulary. In yet another study on pre-service English language teachers' perception of the use of podcast, Guler and Ozkan (2018) found that the participants had a positive view of podcasts in general and intend to use the podcasts in their future teaching careers. A more recent qualitative and quantitative study by Sendag, Gedik, Caner, and Toker (2017) investigated the effects of mobile-extensive-podcast listening activities on listening, speaking, critical thinking skills and critical thinking dispositions as well as listening strategy development of pre-service English teachers. Interestingly enough, they found no meaningful relationship. That is, mobile intensive-podcast-listening had no significant impact on improving the participants' listening, speaking, critical thinking skills, and listening strategies. As is seen, these studies, which focused on the relationship between listening to podcasts and its impact on participants' listening skills and their perceptions, produced conflicting results. On top of that, none has focused on the impact of creating podcasts on improving English pronunciation skills. Motivated by this need, the present study aims to investigate EFL freshmen's perceptions of podcasting and its impact on their pronunciation skills. With these general goals in mind, the present study aims to answer the following research questions:

1. What are EFL freshmen's perceptions of the impact of cretaing pronunciation podcasts on their pronunciation skills?

2. To what extent does podcasting have an impact on the pronunciation skills of EFL freshmen?

\section{METHOD}

\section{Research Design}

The present study adopted a qualitative design grounded in a hermeneutic approach in order to gain a thorough understanding of the research problem, explain the situation, and understand how listening to and creating podcasts impact pronunciation skills and participants' perceptions (Baxter \& Jack, 2008). As the review of the available literature has shown, the issue had not been studied extensively using a qualitative approach in Turkey. As case study research design is an in-depth practical investigation of a current event or a phenomenon in the actual context (Yin, 2009), and it "facilitates exploration of a phenomenon within its context using a variety of data sources" (Baxter \& Jack, 2008, p. 544), a holistic single-case study design serves the purposes of the this study well. Thus, we used a single case exploratory study, adopting Yin's (2009) universally accepted six-stage case study process: plan, design, prepare, collect, analyze and share.

\section{Participants}

This study was conducted with the participation of 80 EFL freshmen, who enrolled in an obligatory "Listening and Pronunciation I" course at a Turkish state university in the 2017-2018 academic year. These freshmen are students who are trained to be teachers of English. The participants had no prior listening instruction or pronunciation instruction except for occasional repetition of decontextualized words in passing. One of their obligatory courses as freshmen is a two-hour "Listening and Pronunciation I" course, which covers a variety of issues: segmental and suprasegmental features of English phonology, speech organs, IPA symbols, 
macro and micro listening skills, and strategies aiming to develop listening comprehension skills in English. Data were collected from all of these 80 freshmen, who carried out the same tasks in and outside the class. However, only 20 of these freshmen who completed all the tasks intact and were available at all the times were interviewed.

\section{The Context}

The initial endeavor of the project started with the development of the web-based component of the course. A freely available and easy-to-use learning management system (LMS) was selected as the online course delivery platform for the course. The LMS was preferred due to its interface, which is visually familiar to users such as popular social networking websites. This LMS allows instructors to post assignments, grade and annotate submissions, give online tests, conduct discussions, send updates, share resources, and even utilize third-party apps seamlessly from any mobile or internet accessed device. The LMS also allows users to provide feedback to any uploaded work, podcasts in our case, on the site.

\section{The Procedure}

Before the project began, the participants were given detailed information about the project and were trained on how to use the LMS effectively and how to create podcasts. During the 14-week-long project, all of the participants produced 12 podcasts outside the class. These 12 podcasts included three podcasts on segmental features of English (i.e., production of vowels and consonants in word-initial, word-mid, and wordfinal); six podcasts on supra-segmental features of English (i.e., stress; word stress, phrase stress, sentence stress; intonation; aspects of connected speech; linking, elision, and assimilation), and three podcasts on extemporaneous speech. The participants created their podcasts using their mobile phones and/or computers and uploaded them to the online courseware that accompanied the course.

Table 1: Topics covered during the instructional time

\begin{tabular}{cccc}
\hline Week & Subject & Week & Subject \\
\hline 1 & Speech organs & 8 & Connected Speech (Assimilation) \\
2 & IPA symbols & 9 & Stress (syllable) \\
3 & Consonants & 10 & Stress (word, phrase, sentence) \\
4 & Consonants & 11 & Stress (word, phrase, sentence) \\
5 & Vowels & 12 & Stress (word, phrase, sentence) \\
6 & Monophthongs, diphthongs and tripthongs & 13 & Intonation \\
7 & Connected Speech (Liaison and elision) & 14 & Intonation \\
\hline
\end{tabular}

Within the scheduled syllabus of this course, several issues related to pronunciation in English were covered in face-to-face class hours over a period of fourteen weeks. Following the training of the participants in the use of the web-component of the course, the first two weeks of the project were spent familiarizing the participants with speech organs and IPA symbols. During the last 12 weeks, the participants produced a four to six-minute-long podcast every week on segmental and suprasegmental features of English, topics covered in the class, and they created their own pronunciation podcasts on the assigned segmental and suprasegmental features of English, which were available in their books and in audio files. They were encouraged to listen to, repeat and record the assigned language features as many times as they wished and to upload their final productions outside of the class to the online component of the course that was secured for the project. The final three podcasts were spared for extemporaneous speech on topics of their own choice. 


\section{Data Collection Tools and Process}

Various data gathering instruments were employed to reach reliable data. Although the foremost data gathering instrument of the present study is the transcripts of semi-structured interviews, other instruments were used to triangulate the findings of the this study, such as investigator notes, dashboard activity records, podcasts created by the participants, as well as peer feedback given on the discussion board. Mainly three questions were asked: (1) What is your opinion of the pronunciation podcast creation project before and after the project? (2) What do you think about the pronunciation podcast creation project? (3) Did creating pronunciation podcast have an influence-positive or negative-on your pronunciation skills? The investigator notes consisted of the notes the first writer, who was also the teacher of the course, took during the project. Dashboard activity records included the feedback the participants gave to one another and comments they made about one another's recordings during the project. Both the investigator notes and the dashboard activity records were considered and made use of during data analysis to clarify and cross-check the data gathered in the semi-structured interviews.

\section{Data Analysis}

Since the key objectives of qualitative analysis is to identify conceptual similarities/differences and to discover types, classes, sequences, processes, patterns or wholes (Jorgensen, 1989), the data analysis of the present study consisted of examining, categorizing, tabulating and recombining evidence to draw empirically based conclusions (Yin, 2009). Bearing these objectives in mind, the recordings were transcribed verbatim and transferred to a word document, which were then shown to the interviewees for confirmation. The data set was then subjected to classical content analysis, which counts themes or codes to detect/identify the most common or recurrent concepts. The initial step in content analysis started with reading the interview transcripts, observational notes, and other relevant documents obtained from the analytics and performance tracking records of the LMS. After gathering the preliminary notes used to formulate the initial categories, themes and relationships, the obtained data were "pre-coded" (Layder, 1998) by researchers manually and independently by highlighting or underlining significant participant quotes. Then, some preliminary words or tentative ideas for codes were recorded through a holistic coding concept. The second coding cycle was held through the combination of nvivo coding and pattern coding; thus, the terms and phrases used by the participants were examined in detail to figure out the patterned variation in the gathered data. Finally, the coded data were categorized and recombined to draw empirically based conclusions through analytical generalizations. The identified codes then led to various sub-categories and categories. The researchers reviewed the categories again to identify and remove any overlapping ones and finalized the "coding and retrieving process" (Patton, 2002). The data were analyzed through cross-case analysis, involving an indepth exploration of similarities and differences across the data sources with a view to supporting empirical generalizability and theoretical predictions. The researchers analyzed and coded the data independently of each other after a training and norming session of coding $10 \%$ of the data. The comparison of coding yielded 87\% agreement according to inter-rater reliability formula of Miles and Huberman (1994). A third rater, a Turkish linguist who is specialized in content analysis and familiar with the categories was consulted for the discrepancies. The three coders analyzed those discrepancies and reached full agreement. The third coder's participation in the coding process helped complete the process without any bias. Finally, the emerging themes and sub-themes were compared and discrepancies were discussed to reach a consensus. After the negotiations, the consistency between the researchers was .82 using the Miles and Huberman's (1994) reliability formula, which is within the acceptable range. The coders came up with two categories: Positive and negative. The positive category includes linguistic (L), pedagogical (Ped.), psychological (P), and technological $(\mathrm{T})$ sub-categories, whereas the negative category contained only two sub-categories: computer illiteracy $(\mathrm{CI})$ and quality of internet connection. 


\section{RESULTS}

As regards the perceived impact of podcasting, the results indicated that the participants had positive views of podcasting and that the majority of them (85\%) agreed that podcasting helped them improve their pronunciation skills and develop positive views towards podcasting. In order to explore the attitudes of the participants in detail, we first inquired about the participants' expectations of podcasting prior to and after the implementation. Based on the content analysis of the interview questions, it was found that the responses varied: some were satisfied with the podcasting, some were doubtful of its efficacy, and some were dissatisfied with it.

In terms of participants' initial expectations, the analysis revealed that roughly $15 \%$ of the participants had had moderately positive attitudes prior to podcasting. Moreover, we found that only $10 \%$ of the participants had had relatively positive expectations of it and hoped to gain better pronunciation skills. For instance, one of the participants expressed his/her enthusiasm:

At the beginning of the term, I was excited about recording my own voice and expected it to improve my pronunciation a bit (Participant 6).

On the opposite end of the cline were those participants who had higher expectations (5\%) and had expected to dwell on intensive pronunciation exercises as well as experience a more interactive process with the teacher. The initial expectation of one of the participants was as follows:

I was hoping it would help me improve my pronunciation. I thought that we would get face to face feedback, and we would be tutored in the class to correct our mistakes (P 4).

It should be noted that the demographic data about the participants who had higher expectations revealed that they all had had prior experience on similar web-enhanced learning tools during their intensive English language education at English preparatory school in the university.

The analysis of the data also revealed that in between these two extremes were the majority of the participants $(85 \%)$, who had complicated feelings, ranging from doubt to skepticism to fear of the unknown. For instance, one of those participants who initially thought that the procedure would be complicated stated:

At the beginning of the term, I thought that podcasting would be complicated, and it would bore us (P 15).

Similarly another participant expressed his skepticism of it saying:

At the beginning of the term, I thought that it would be difficult to use this LMS because I've never used such a thing. I thought something would be sophisticated, and therefore I felt confused at first (P 1).

Likewise, another participant who thought that it would be a burden said:

At the beginning of the term, I had my own suspicions regarding podcasting because I thought that it would take a lot of time; therefore, I thought I would not like it (P 10).

To further compare the participants' expectations at the beginning and end of the study, they were asked to what extent their expectations came true at the end. The analysis of the data illustrated that while the participants who had positive attitudes (10\%) maintained their stance towards podcasting, only one of the $5 \%$ of the participants who had negative feelings about and expectations of it changed his/her position in a positive way. The expectations of the other $4 \%$ remained negative. For instance, the participant who expressed that his/her attitude did not change said;

My opinion about podcasting still hasn't changed. I still find it sophisticated and a bit challenging (P15).

The greatest change was observed in the position and stance of those who had neither positive nor negative expectations. The data of the first round explicated that the attitudes of a great number of the participants $(85 \%)$ were identified as undecided, skeptical, suspicious, anxious, and worried about podcasting. However, at the end, we saw that expectations of the $80 \%$ of this group had changed in a positive way. Concerning this change, one of the participants stated:

At the beginning, I had worries about it if it was necessary to use this app. However, I thought about positive sides, and I changed my mind (P 10). 
Another participant verbalized the same stance saying:

Yes, my opinion has changed, because at the beginning, as I expressed before, I thought that I would face some problems in uploading my homework and was a bit nervous. But as the time passed, I thought that this experience would have positive impact on us when we begin teaching. Actually I might use such apps in my own teaching as well (P 6).

The in-depth analysis of the data brought some sub-themes that could be named as purely linguistic gains, technology-related issues, pedagogical, social, and psychological gains and other benefits (see table 2).

Table 2. Themes and sub-themes

\begin{tabular}{lllll}
\hline & positive (\%) & & negative (\%) & 10 \\
\hline \multirow{3}{*}{ Themes } & linguistic (L) & 80 & computer illiteracy (CI) & 15 \\
& pedagogical (Ped.) & 85 & quality of internet connection (QIC) & \\
& psychological (P) & 85 & & \\
\hline
\end{tabular}

Positive views on creating pronunciation podcasts

As seen in table Positive views includes linguistic, pedagogical, psychological, and technological. As for the linguistic gains, almost all of the participants declared that they made great improvements in their pronunciation skills, which was reflected in the increase in their final exam scores as well. The main reason behind the increase was that the process helped them relax in producing something in front of an audience. Although the data unveiled that $80 \%$ of the participants stressed that podcasting helped them improve their pronunciation, $10 \%$ of them stated that it did not do so. Additionally, it was found that the other $10 \%$ of them were still unsure about the positive influence of it on their pronunciation skills. Each and every one of those who acknowledged the positive impact of it on their pronunciation skills underlined the importance of having multiple opportunities as they listened to the audios and recorded their own podcasts. This opportunity helped them pedagogically and psychologically. More than $85 \%$ of the participants who had positive views about podcasting underlined that the unlimited opportunity of recording and listeing to their own pronunciation production eased their stress of speking in front of an audience. In this aspect, one the participant expressed his/her opinion:

I think podcasting did not have any negative sides but many positive sides. First of all, we all improved our pronunciation, because we tried until we succeed it (P19).

Likewise, another participant expressed:

I clearly see that podcasting contributed to my pronunciation because I was able to hear my own pronunciation.

Thus, I had the chance to evaluate myself and improve my pronunciation (P17).

Talking about the same positive aspect of podcasting, some participants drew attention to yet another aspect of it; that is, the flexibility and freedom in the tryouts of podcasting before submitting the final version of their podcasts. For instance, one of the participants expressed his/her thoughts as:

I think one of the important aspects of podcasting is saving time. We were able to submit the podcasts whenever we wanted to, but the greatest opportunity we had is to try it as many times as we desire (P 13).

Yet another noteworthy aspect of podcasting was related to finding it worthy of recommendation. The analysis of the data revealed that all of the participants, even the $10 \%$ who underlined that the project did not contribute to their pronunciation at all, stated that they would definitely recommend podcasting to teachers, EFl freshmen and prospective students who would like to gain progress in the target language pronunciation. For instance, one of the participants stated:

I would definitely recommend using such apps both to students and teachers as it enables them to reach the content and peers whenever needed (P 7). 
Like the participant above, the following participant underlined its usefulness despite its flaws saying:

Yes, certainly I would. Regardless of the problems I had while using the LMS, I think all of the activities were useful. It's a good way to collect all the homework in one place (P 6).

In contrast to this great majority, $10 \%$ of the participants stated that podcasting did not help them improve their pronunciation skills at all. One of the participants said crediting his/her previous pronunciation skills stating:

It is impossible for me to say podcasting help me improve my pronunciation. It is not a matter of question. Because, what we did in this course about pronunciation is almost similar to those what I did without any such productions ( $p$ 5).

It should be noted here that a distinctive feature of this group is that all of them had similar prior experiences in their intensive English language education at English Preparatory School.

Additionally, it was found that there were some participants (10\%) who were still unsure of the contribution of podcasting. One of those participants who credited the difficulty of fossilized pronunciation errors stated:

I hope it has. Although I am not sure about that. Most of the things we do in class and as homework are familiar to me. I have been using English actively for almost 10 years now, so if there are words that I pronounce incorrectly, it is really difficult for me to change their pronunciation. Old habits die hard (P 2).

In another sub-theme, which is related to technological issues, we saw that $30 \%$ of those who found the project useful underlined that they developed their computer-literacy skills during the process. For instance, one of the participants underlined:

Podcasting helped me learn to use the technology efficiently. I did not know anything about this sort of technology and web-enhanced thing before (P16).

Another widely expressed sub-theme is having the opportunity to listen to their own voice and productions. One of the participants expressed his/her thoughts as:

I think the positive side would be that we can hear ourselves and see the way we pronounce the words before sending them, which helps our pronunciation to become better. I don't see any negative sides (P18).

Negative views on creating pronunciation podcasts

When it comes to the cons of podcasting, we saw that the negative attitudes centered around two main issues: computer literacy (10\%) and lack of quality of internet access (15\%). As can be seen, the former is directly related to the participants and their computer skills, whereas the latter lies outside the control them. The following excerpts reflect their attitudes on the issue:

Negative side of podcasting was the fact that I was not able to upload my recording from my phone. I had to send my files from my phone to a PC, and only then I was able to do that, which means that the only way to submit my homework when I had access to a PC (P 4).

The only negative side that I can think of is the poor Internet connection, I know it is related to the internet access, but when Internet connection is weak, we cannot make contact and upload our homework on time (P 11).

Another recurrent sub-theme was related to the spatio-temporal limitations of the classroom. That is, we learned to what extent podcasting freed participants from the spatio-temporal limitations of the classroom. We found that one of the most frequently mentioned benefits of creating podcasts was related to spatiotemporal limitations of the classroom. For instance, one of them said:

If I am to talk about the pros of podcasting, everybody was able to easily submit their assigned podcasts at anytime and anywhere they wanted to. We easily delivered our assignments (P 6).

\section{DISCUSSION}

The results have demonstrated that the participants had positive view about podcasting and had linguistic, pedagogical, social, and psychological gains from podcasting. For instance, most of the participants stated that the project helped them improve their pronunciation skills by allowing them to practice pronunciation at their convenience. The great majority of the participants underlined that their pre-podcasting expectations 
regarding improving pronunciation were fully met. This observation supports findings of some previous research on the same issue (e.g., Ducate \& Lomicka, 2009; Gorjian et al., 2013; Lord, 2008; Tanner \& Landon, 2009). For instance, Lord's (2008) study showed that her participants developed positive attitudes towards pronunciation and found it useful. The same issue was voiced by Ducate and Lomicka's (2009) participants, underlining that podcasting helped them develop positive attitudes towards pronunciation.

Another contribution of the study is pedagogical. As the one course our participants had had until then, they stated that they would take it as a model for teaching pronunciation and dealing with issues of pronunciation when they start teaching English. This realization supports Guler and Ozkan's (2018) finding that underlines their participants' positive views of podcasts and their intention to integrate podcasting into their teaching.

Yet another area of contribution from this study involves social skills. For the first time in their lives, almost all of the participants produced podcasts and received feedback from others. Even though the speaking practice was virtual, this process helped them overcome their fear of speaking in front of an audience.

Another way in which the study contributed positively is psychological in that it discovered participants' excitement and enthusiasm. The participants were intensely excited because they would participate in something completely new to them: they would record their own voices and listen to them. The contentment of accomplishing and creating something on their own seemed to enhance their feelings of self-worth and esteem. This sentiment is in accord with that of Rosell-Aguilar (2007), who maintains that podcasting is profoundly interrelated with constructivism in which learners construct knowledge through active exploration, observation, processing and interpretation. This observation supports findings of some previous research on the same issue. For instance, Lord's (2008) study showed that her participants developed positive attitudes towards pronunciation and found it useful. The same sentiment was voiced by the participants of Ducate and Lomicka (2009), underlining that podcasting helped them develop positive attitudes towards pronunciation and earned their appreciation.

In sum, this study has broadened our horizons regarding the use of web-enhanced mobile assisted language learning tools and devices in creating pronunciation podcasts. It has demonstrated that creating pronunciation podcasts outside the classroom can help use time much more efficiently. This study has implications for English language teachers and Listening and Pronunciation teachers. The findings of the study have revealed that English language teachers (ELT) teachers will have more freedom as to how they spend their time in and outside of the classroom by creating pronunciation podcasts outside the classroom. Likewise, listening and pronunciation teachers will have considerable leeway to spend their time in the classroom. They can spend more of their time on other important aspects and issues of their course.

\section{CONCLUSION}

The results of our study are encouraging, not only because they support findings from previous research, indicating that there is room for learners to improve their pronunciation skills through web-enhanced learning tools, but also the possible role podcasting can play in language learning endeavors. This observation is quite important given the tendency of language teachers to view pronunciation as the least useful of the basic language skills and to sacrifice pronunciation teaching for other areas of the language (Elliott, 1995). Teachers' inclinations to ignore pronunciation compounds the already problematic issue in many countries, where teachers and learners have to grapple with spatio-temporal limitations of the classroom in listening and pronunciation courses in ELT programs. Last but not least, the results of our study led us to conclude that podcasting freed learners to a great extent from the spatio-temporal limitations of the classroom, allowing them to study and practice pronunciation at their own convenience, and benefitting them linguistically, pedagogically, socially, and psychologically. Given these benefits, ELT teachers' consciousness on creating pronunciation podcasts should be raised. Also, Listening and Pronunciation course teachers could be encouraged to integrate web-based practices such as podcasting into their courses. Policy makers and materials developers could be informed about the benefits of creating pronunciation podcasts. 
The overall promising findings of the study should be interpreted cautiously in the light of several limitations. The first one pertains to the nature of the study. In such a study, the influence of podcasting on the intelligibility and accentedness of the participants' pronunciation might be investigated. Another limitation of the study is related to time spent on the project. As it will be appreciated, a 14-week-long project may not be long enough. The final limitation of the study is related to providing instructor feedback on podcasts. Further studies may examine the influence of face-to-face instructor feedback. In spite of these limitations, in listening to the participants' voices on creating podcasts through this study, we saw the urgent need for devoting extra time on pronunciation and devising web-enhanced language learning tools to be used in an outside of the classroom.

\section{BIODATA and CONTACT ADDRESSES of AUTHORS}

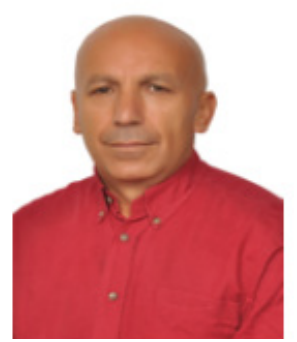

Dr. Huseyin KAFES is an associate professor of English at Akdeniz University. Dr. Kafes holds an MA and a Ph.D. in ELT from Anadolu University. He did his postdoctoral research on academic writing at Arizona State University. He is currently working as a lecturer at Akdeniz University, Turkey. His main interests are linguistics, academic writing, discourse analysis, rhetoric, and TEFL. He has various research articles published in international refereed journals covering topics such as academic writing, pronunciation, and teacher education

\section{Huseyin KAFES}

Akdeniz University, Faculty of Education

English Language Teacher Education Program

07070 Antalya, Turkey

Phone: +90 $2422274400-4611$

e-mail: hkafes@akdeniz.edu.tr

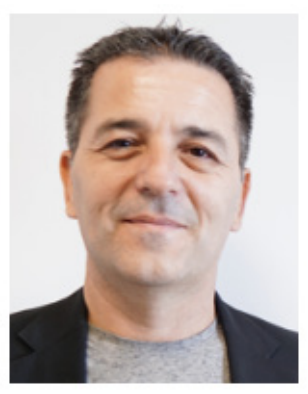

Dr. Mustafa CANER is an Associate Professor on Open and Distance Education in Higher Education and currently working as a lecturer at Akdeniz University, Turkey. Dr. Caner holds bachelor's and master's degrees in ELT from Ondokuz Mayis University, Turkey, and a Ph.D. degree in ELT from Anadolu University, Turkey. His areas of research include issues concerning foreign language teacher education and technology use in foreign language education. He has various research articles published in international refereed journals and book chapters covering topics such as blended learning, distance education, and teacher education.

\section{Mustafa CANER}

Akdeniz University, Faculty of Education

English Language Teacher Education Program

07070 Antalya, Turkey

Phone: +90 2423102082

e-mail: mcaner@akdeniz.edu.tr 


\section{REFERENCES}

$\mathrm{Alm}$, A. (2013). Extensive listening 2.0 with foreign language podcasts. Innovation in Language Learning and Teaching, 7(3), 266-280.

Basaran, S. \& Cabaroglu, N. (2014). Language learning podcasts and learners' belief change. TESL-EJ,, The electronic journal of English as a Second Language, 17, 4, 1-32.

Baxter, P., \& Jack, S. (2008). Qualitative case study methodology: Study design and implementation for novice researchers. The Qualitative Report, 13(4), 544-559.

Breitkreutz, J., Derwing, T. M., \& Rossiter, M. J. (2001). Pronunciation teaching practices in Canada. TESL Canada Journal, 19, 51-61.

Burgess, J., \& Spencer, S. (2000). Phonology and pronunciation in integrated language teaching and teacher education. System, 28, 191-215.

Buss, L. (2016). Beliefs and practices of Brazilian EFL teachers regarding pronunciation. Language Teaching Research, 20, 619-637.

Carvalho, A. A. A., \& Aguiar, C. (2009). Impact of podcasts in teachers' education: From consumers to producers. Proceedings of the 20th international conference of the society for information technology and teacher education, (pp. 2473-2480). Charleston, South Carolina, USA.

Celce-Murcia, M., Brinton, D., Goodwin, J., \& Griner, B. (2010). Teaching pronunciation: A course book and reference guide. New York: Cambridge University Press.

Derwing, T. M. (2018). Putting an accent on the positive: New directions for L2 pronunciation research and instruction. International Symposium on Applied Phonetics, 19-21 September 2018, Aizuwakamatsu, Japan.

Derwing, T. M., \& Munro, M. J. (2005). Second language accent and pronunciation teaching: A researchbased approach. TESOL Quarterly, 39, 379-397.

Diem, R. (2005). Podcasting: A new way to reach students. The Language Teacher, 29(8), 45-46.

Ducate, L., \& Lomicka, L. (2009). Podcasting: An effective tool for honing language students' pronunciation. Language Learning and Technology, 13, 66-86.

Elliott, A. R. (1995). Foreign language phonology: Field independence, attitude, and the success of formal instruction in Spanish pronunciation. Modern Language Journal, 79,530-542.

Facer, B. R., \& Abdous, M. (2010). Academic podcasting and mobile assisted language learning: Applications and outcomes. Hershey: IGI Global.

Faramarzi, S., \& Bagheri, A. (2015). Podcasting: Past issues and future directions in instructional technology and language learning. Journal of Applied Linguistics and Language Research, 2(4), 207-221.

Foote, J. A., Holtby, A. K., \& Derwing, T. M. (2011). Survey of the teaching of pronunciation in adult ESL programs in Canada, 2010. TESL Canada Journal, 29, 1-22.

Godwin-Jones, R. (2005). Skype and podcasting: Disruptive technologies for language learning. Language Learning and Technology, 9(3), 9-12.

Gromik, N. (2008). EFL learner use of podcasting resources: A pilot study. The JALT CALL Journal, 4(2), 47-60.

Guler, S., \& Ozkan, Y. (2018). Podcast applications in pre-service language teacher education from a constructivist perspective. World Journal on Educational Technology: Current Issues. 10(3), 131-141.

Harika, H., \& Kocoglu, Z. (2016) The application of podcasting as an instructional tool to improve Turkish EFL learners' speaking anxiety. Educational Media International, 53(4), 313-326.

Hardison, D. (2004). Generalization of computer-assisted prosody training: Quantitative and qualitative findings. Language Learning \& Technology, 8(1), 34-52.

Henderson, A., Frost, D., Tergujeff, E., Kautzsch, A., Murphy, D., Kirkova-Naskova, A., ... \& Curnick, L. (2012). The English pronunciation teaching in Europe survey: Selected results. Research in Language, 10(1), 5-27. 
Hismanoglu, M. (2010). Online Pronunciation Resources: Hobbies or Fobbies of EFL Teachers? IJONTE, $1(2), 40-53$.

Huensch, A. (2018). Pronunciation in foreign language classrooms: Instructors' training, classroom practices, and Language Teaching Research, 1-20.

Jones, R. H. (1997). Beyond "listen and repeat": Pronunciation teaching materials and theories of second language acquisition. System, 25, 103-112.

Jorgensen, D. L. (1989). Participant observation: A methodology for human studies. Newbury Park, CA, Sage Publications.

Layder, D. (1998). Sociological practice: Linking theory and research. London: Sage

Lord, G. (2008). Podcasting communities and second language pronunciation. Foreign Language Annals, 41(2), 364-379.

MacDonald, S. (2002). Pronunciation: Views and practices of reluctant teachers. Prospect, 17, 3-18.

Martin, P. (2004). Winpitch LTL II, a multimodal pronunciation software. Paper presented at InSTIL/ICALL 2004 Symposium on Computer Assisted Learning, Venice, Italy.

McGarr, O. (2009). A review of podcasting in higher education: Its influence on the traditional lecture. Australasian Journal of Educational Technology, 25(3), 309-321.

Meng, P. (2005). Podcasting and vodcasting: A white paper. [White Paper]. Retrieved March, 2019 from http://edmarketing.apple.com/adcinstitute/wp-content/Missouri_Podcasting_White_Paper.pdf

Miles, M. B., \& Huberman, A. M. (1994). Qualitative data analysis (2nd ed.). London: Sage.

O'Bryan, A., \& Hegelheimer, V. (2007) Integrating CALL into the classroom: The role of podcasting in an ESL listening strategies course. ReCALL, 19(2), 162-180.

Patton, M. Q. (2002). Qualitative research and evaluation methods, (3rd ed.). Newbury Park, CA, USA: Sage.

Pennington, M. C. (1989). Teaching pronunciation from the top down. RELC Journal, 20(1), 20-38.

Robin, R. (2007). Commentary: Learner-based listening and technological authenticity. Language Learning and Technology, 11(1), 109-115.

Rosell-Aguilar, F. (2007). Top of the pods-in search of a podcasting "pedagogy" for language learning. Computer Assisted Language Learning, 20(5), 471-492.

Rosell-Aguilar, F. (2013). Podcasting for language learning through iTunes U: The learner's view. Language, Learning and Technology, 17(3), 74-93.

Seferoglu, G. (2005). Improving students' pronunciation through accent reduction software. British Journal of Educational Technology, 36(2), 303-316.

Stanley, G. (2006). Podcasting: Audio on the Internet comes of age. TESL-EJ, 9(4), 1-7.

Swain, M. (1985). Communicative competence: Some roles of comprehensible input and comprehensible output in its development. In Gass, S. and Madden, C. (Eds.), Input in second language acquisition, (pp. 235-256). New York: Newbury House.

Swain, M., \& Lapkin, S. (1995). Problems in output and the cognitive processes they generate: A step towards second language learning. Applied Linguistics, 16, 371-391.

Sendag, S., Gedik, N., Caner, M., \& Toker, S. (2017). Effects of mobile-intensive-podcast listening on listening, speaking, and critical thinking skills of pre-service English teachers. Educational Technology Theory and Practice, 7(2), 94-112.

Tanner, M. W., \& Landon, M. M. (2009). The effects of computer-assisted pronunciation readings on ESL learners' use of pausing, stress, intonation, and overall comprehensibility. Language Learning \& Technology, 13(3), 51-6.

Young, D. J. (2007). iPods, MP3 players and podcasts for FL learning: Current practices and future considerations. NECTFL Review, 60, 39-49.

Yin, R. K. (2009). Case study research: Design and methods (4th Ed.). Thousand Oaks, CA: Sage. 